\title{
An Effective Option for the Repair of Facial Defects: V-Y Advancement Flaps and Modifications
}

\author{
Handan Derebașınlıoğlu', Sarper Yilmaz², Kadriye Ipek Uzunoglu³ \\ 1 Department of Plastic Reconstructive and Aesthetic Surgery, Faculty of Medicine, Sivas Cumhuriyet University, Sivas, Turkey \\ 2 Department of Plastic Reconstructive and Aesthetic Surgery, Faculty of Medicine, Ufuk University, Ankara, Turkey \\ 3 Department of Plastic Reconstructive and Aesthetic Surgery, Konya Training and Research Hospital, Konya, Turkey
}

Handan Derebaşınlıoğlu, ORCID: 0000-0003-1412-4672

Sarper Yilmaz, ORCID: 0000-0002-3078-2264

Kadriye Ipek Uzunoglu, ORCID: 0000-0003-4186-9186

\begin{abstract}
Objective: V-Y advancement flaps are pliable local flaps that can be used in nearly every part of the body with relatively minimal technical difficulty. These flaps provide the best color and quality match, especially in the facial region. With effective planning, donor site morbidity can be acceptable, even on the face.
\end{abstract}

Methods: The results of 38 patients who underwent 53 $\mathrm{V}-\mathrm{Y}$ advancement flap facial reconstructions were analyzed retrospectively. The defects were evaluated according to their anatomical region, etiology, postoperative complications, and final aesthetic results.

Results: V-Y advancement flaps were used for defects that were either not amenable to primary repair or had a high risk of cosmetic distortion. The defects were located in the cheek (9 patients), nasolabial fold (7 patients), nose (6 patients), forehead (5 patients), preauricular area
(3 patients), infraorbital region (3 patients), lower lip (1 patients), gingivobuccal sulcus (2 patients), and medial canthal region (2 patients). In 32 patients, the primary pathology was malignant tumor (22 basal cell carcinomas, 9 epidermoid carcinomas, 1 malignant eccrine poroma). Etiologies of the other patients' defects were benign tumors $(n=2)$, traumatic wounds $(n=2)$, and contractures $(n=2)$.

Conclusions: Despite the widespread use of V-Y flaps in surgical practice, the technique continues to demonstrate additional advantages, particularly in facial reconstruction. They are not only applicable for medium and small defects, but can be used for all defects with sufficient surrounding tissue. They enable various modifications and the elevation of multiple flaps.

Keywords: Surgical flaps, reconstructive surgical procedures, face. 


\section{Introduction}

An ideal reconstructive surgery should repair a defect with adequate and appropriate soft tissue as well as satisfying patient expectations as much as possible. In most cases, a better color and quality match can be achieved with adjacent tissues. ${ }^{[1]}$ This is especially true for the facial region, which contains a number of aesthetic units and subunits. When the defect includes more than one aesthetic unit and/or subunit, it poses an extra challenge for reconstructive surgeons.

$\mathrm{V}$-Y flaps are commonly used in nearly every part of the body with considerable success. The advantages of this design are well established, ${ }^{[2]}$ and numerous modifications of the technique have been published. ${ }^{[3-6]}$ The flap is supplied by the perforating vessels entering the flap base and the use of adjacent soft tissues usually offers a better color and quality match. ${ }^{[7]}$ The presence of adipose tissue affects the mobility of the flap. Both the thickness and the elastic and loose nature of the subcutaneous tissue facilitate advancement of the flap. When additional mobility of the flap is required, a couple of perforators can be identified and preserved, thereby providing enhanced mobility. With this maneuver, it may also be possible to rotate the flap. Basal perforators also enable the planning of large flaps, even in the facial region. Flap dissection is simple, the learning curve is acceptable, and operative time is relatively short. Donor site morbidity is generally acceptable. These flaps can also be safely used to repair mucosal defects.

The aim of the present study was to present $\mathrm{V}-\mathrm{Y}$ advancement flaps and modifications used for facial reconstructions in our center and to discuss the aesthetic outcomes and complications.

\section{Materials and Methods}

The results of $53 \mathrm{~V}-\mathrm{Y}$ advancement flaps used in reconstructions involving the facial region in 38 patients were analyzed retrospectively. Approval for the study was obtained from the Cumhuriyet University Ethics Committee (decision no: 2018-04\37, dated: April 30, 2018). The defects were evaluated according to their anatomical region, etiology, postoperative complications, and final aesthetic results. All operations were performed by the same two surgeons (H.D. and K.I.U.).

\section{Technique}

Vasoconstriction was induced with an injection of $1 / 100,000$ epinephrine. All flaps were planned as classical subcutaneous pedicle V-Y flaps. However, during flap elevation we identified and preserved a few perforator vessels, albeit small. This maneuver allowed us to maximize flap mobility. For larger defects, flap dissection was extended through the muscle fibers, which facilitated tension-free closure if larger perforators were available. For defects in which the desired reconstruction could not be achieved with a single flap, bilateral V-Y flaps were utilized.

\section{Results}

Demographic data and other patient characteristics are given in Table 1 . The $\mathrm{V}-\mathrm{Y}$ advancement flap technique was used in 38 patients whose defects were either not amenable to primary repair or had a high risk of cosmetic distortion. In these patients, a total of $53 \mathrm{~V}$-Y flaps were used. The patients ranged in age from 6 to 90 years (median age: 60.08 years). Twelve defects were reconstructed with bilateral V-Y flaps, and in 4 patients various other flap designs (Fricke, glabellar, bilobed) were used in combination with $\mathrm{V}-\mathrm{Y}$ flaps. In 2 patients with mucosal contractures, gingivobuccal sulcus reconstruction was performed successfully with V-Y flaps, and V-Y commissuroplasty was also added in 1 patient. In 1 patient, $3 \mathrm{~V}$-Y flaps were performed in the same session. Total flap loss was not observed in our series. There was partial flap loss in a patient with a large dorsal nasal defect who was treated with bilateral cheek $\mathrm{V}-\mathrm{Y}$ flaps, and the wound healed by secondary intention in 3 weeks. Transient venous ischemia occurred in a patient with a large forehead defect reconstructed with $3 \mathrm{~V}-\mathrm{Y}$ flaps, but the outcome was uneventful. In another patient with a forehead defect reconstructed using bilateral V-Y flaps, minimal but continuous oozing was observed, probably due to the use of low molecular weight heparin for his existing cardiological problems. After lowering the dose, the oozing ceased on postoperative day 2. In most patients, cosmetic outcome was more than satisfactory. The functional and esthetic results were impressive in many patients, especially with relatively large defects for which one might easily consider microvascular flap surgery. Here, we present 4 such cases.

\section{Case 1}

A 70-year-old man (patient 22) was admitted to our department due to a $2 \times 2 \mathrm{~cm}$ ulcerated lower lip tumor. Incisional biopsy had been performed previously and the histologic examination revealed squamous cell carcinoma (SCC). The tumor was excised with a $1-\mathrm{cm}$ margin and after confirm- 
Table 1. Demographic data and other patient characteristics including localization, etiology, number of flaps and additional flaps used with $\mathrm{V}$-Y flap.

\begin{tabular}{|c|c|c|c|c|c|c|}
\hline Patient & Sex & Age & Localization & Etiology & Additional Flaps & Number of V-Y flaps \\
\hline 1 & Female & 47 & Nasolabial fold & $\mathrm{BCC}$ & & 1 \\
\hline 2 & Male & 51 & Nasolabial fold & $\mathrm{BCC}$ & & 1 \\
\hline 3 & Male & 72 & Preauricular area & $\mathrm{BCC}$ & & 1 \\
\hline 4 & Male & 58 & Nasolabial fold & SCC & & 1 \\
\hline 5 & Male & 80 & Preauricular area & SCC & & 2 \\
\hline 6 & Male & 65 & Cheek & SCC & Fricke & 1 \\
\hline 7 & Male & 65 & Cheek & $\mathrm{BCC}$ & & 1 \\
\hline 8 & Male & 62 & Nasolabial fold & $\mathrm{BCC}$ & & 2 \\
\hline 9 & Female & 52 & Medial canthus & $\mathrm{BCC}$ & Glabellar & 1 \\
\hline 10 & Male & 44 & Cheek & Granuloma & Bilobed & 1 \\
\hline 11 & Female & 70 & Medial canthus & $\mathrm{BCC}$ & Fricke & 1 \\
\hline 12 & Male & 30 & Nasolabial fold & $\mathrm{BCC}$ & & 1 \\
\hline 13 & Female & 63 & Cheek & $\mathrm{BCC}$ & & 1 \\
\hline 14 & Female & 67 & Cheek & Keratoacanthoma & & 1 \\
\hline 15 & Female & 57 & Cheek & $\mathrm{BCC}$ & & 1 \\
\hline 16 & Female & 76 & Cheek & Malignant eccrine poroma & & 2 \\
\hline 17 & Male & 90 & Cheek & SCC & & 1 \\
\hline 18 & Female & 66 & Nose lateral wall & $\mathrm{BCC}$ & & 1 \\
\hline 19 & Male & 64 & Nose lateral wall & $\mathrm{BCC}$ & & 1 \\
\hline 20 & Male & 57 & Nose lateral wall & $\mathrm{BCC}$ & & 1 \\
\hline 21 & Female & 59 & Nasal dorsum & SCC & & 2 \\
\hline 22 & Male & 70 & Lower lip & SCC & & 2 \\
\hline 23 & Male & 49 & Gingivobuccal sulcus & Contracture & & 3 \\
\hline 24 & Male & 45 & Forehead & $\mathrm{BCC}$ & & 2 \\
\hline 25 & Male & 71 & Forehead & Contracture & & 2 \\
\hline 26 & Female & 55 & Forehead & $\mathrm{BCC}$ & & 2 \\
\hline 27 & Male & 38 & Nose & $\mathrm{BCC}$ & & 1 \\
\hline 28 & Female & 74 & Infraorbital & $\mathrm{BCC}$ & & 1 \\
\hline 29 & Female & 66 & Nasolabial fold & SCC & & 1 \\
\hline 30 & Male & 6 & Gingivobuccal sulcus & Traumatic wound & & 1 \\
\hline 31 & Male & 21 & Nose & Traumatic wound & & 2 \\
\hline 32 & Male & 54 & Preauricular area & $\mathrm{BCC}$ & & 1 \\
\hline 33 & Male & 77 & Forehead & SCC & & 2 \\
\hline 34 & Male & 81 & Infraorbital & $\mathrm{BCC}$ & & 2 \\
\hline 35 & Female & 71 & Cheek & SCC & & 1 \\
\hline 36 & Male & 50 & Nasolabial fold & $\mathrm{BCC}$ & & 1 \\
\hline 37 & Female & 70 & Infraorbital & $\mathrm{BCC}$ & & 1 \\
\hline 38 & Male & 82 & Forehead & $\mathrm{BCC}$ & & 3 \\
\hline
\end{tabular}


ing safe surgical margins via frozen section examination, bilateral V-Y flaps were considered for reconstruction. The upper limits of the flaps came up to the oral commissures and were planned as subcutaneous pedicle flaps based on the orbicularis oris muscle, which was carefully preserved in order to facilitate appropriate muscle repair. Advancement of the flaps was very comfortable and muscle repair was effective. The vermillion defect was reconstructed simply by advancing the mucosa of both flaps. A satisfactory result was achieved with good continuity of the orbicularis oris muscle, and microstomy was avoided. The postoperative period was uneventful (Figure 1).

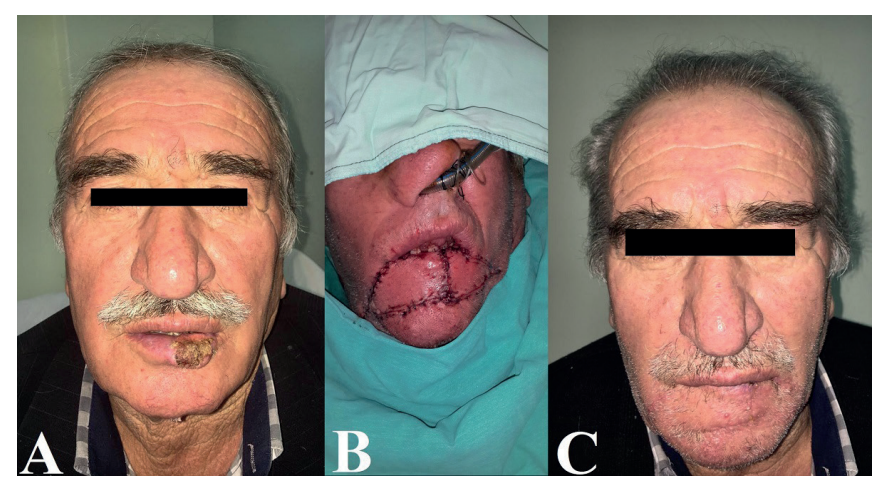

Figure 1. Figure 1. Preoperative (A), intraoperative (B) and postoperative 3-month (C) images of case 1 (patient 22).

\section{Case 2}

A 76-year-old woman (patient 16) was referred to our department with a diagnosis of malignant eccrine poroma. The lesion was situated on the 1 border of the lower eyelid. After excision of the lesion with $1 \mathrm{~cm}$ of surgical margins along with safe margin confirmation via frozen section investigation, the defect was closed with a double opposing subcutaneously pedicled V-Y flap. Preparing a medially based flap and anchoring it superiorly in a double opposing fashion with the other V-Y flap facilitated the support of the lower eyelid and prevented possible ectropion. No complication was observed in the postoperative period (Figure 2).

\section{Case 3}

A 70-year-old woman (patient 37) was admitted to the hospital with the complaint of a long-standing ulceration on the left infraorbital area. Biopsy revealed a poorly differentiated SCC and therefore a wide radical excision was planned. The excision included periosteum and due to the

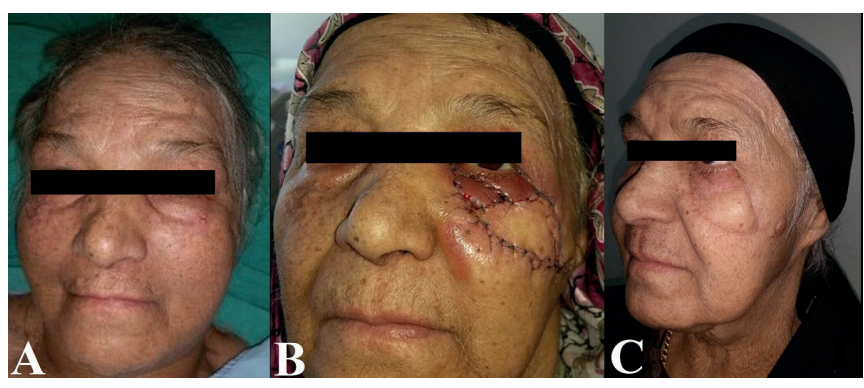

Figure 2. Preoperative (A), intraoperative (B) and postoperative 4-month (C) images of case 2 (patient 16).

confirmed presence of malignant cells in continuity with the medial lower eyelid region by frozen section, an additional excision of the medial third of the lower eyelid was also added. A large V-Y flap including almost all of the cheek tissue was planned. The subcutaneously pedicled flap was prepared and an additional dissection was carefully performed to attain adequate mobility. During this meticulous dissection, 2 moderately sized perforators were identified and preserved. The flap was easily advanced and adaptation was achieved using a maneuver described by Akan et al. ${ }^{[3]}$ This maneuver involves transposing the upper and lower extensions of the V-Y flap into the defect and suturing them to one another. Although Akan et al ${ }^{[3]}$ described this technique as part of bilateral VY advancement flaps, we used it effectively in single V-Y flaps (both in this case and in case 4). The lower part of the flap was anchored directly to the periosteum of the nasal bone with several permanent sutures to eliminate downward traction on the lower eyelid and upper part of the flap. The early postoperative outcome was excellent; a mild ectropion was observed at postoperative 6 months, but it caused very little discomfort (Figure 3).

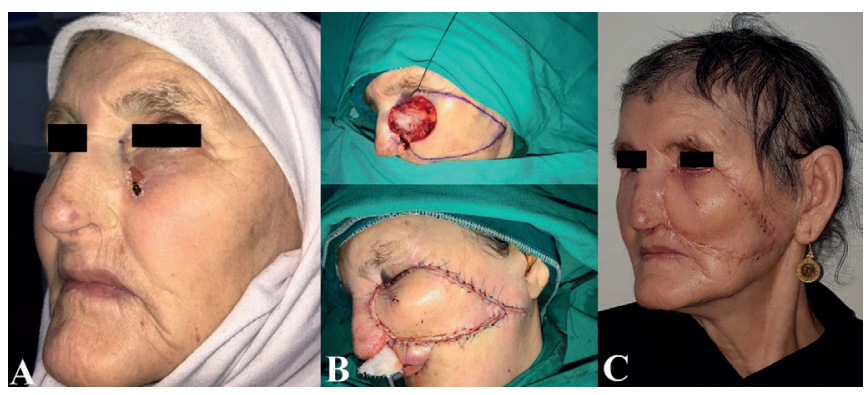

Figure 3. Preoperative (A), intraoperative (B) and postoperative 1-year (C) images of case 3 (patient 37). 


\section{Case 4}

A 66-year-old woman (patient 29) was admitted for a nodular SCC located in the left nasolabial fold. The lesion was close to the alar base and nasolabial fold. The lesion was excised radically with the aid of frozen section. For reconstruction of the large defect, a large V-Y flap including nearly all of the cheek tissue was planned. The subcutaneously pedicled flap was easily advanced and the adaptation was achieved as described in case 3 . This maneuver also allowed a transverse elongation of the flap and made it possible to reconstruct the defect with similar tissues (Figure 4).

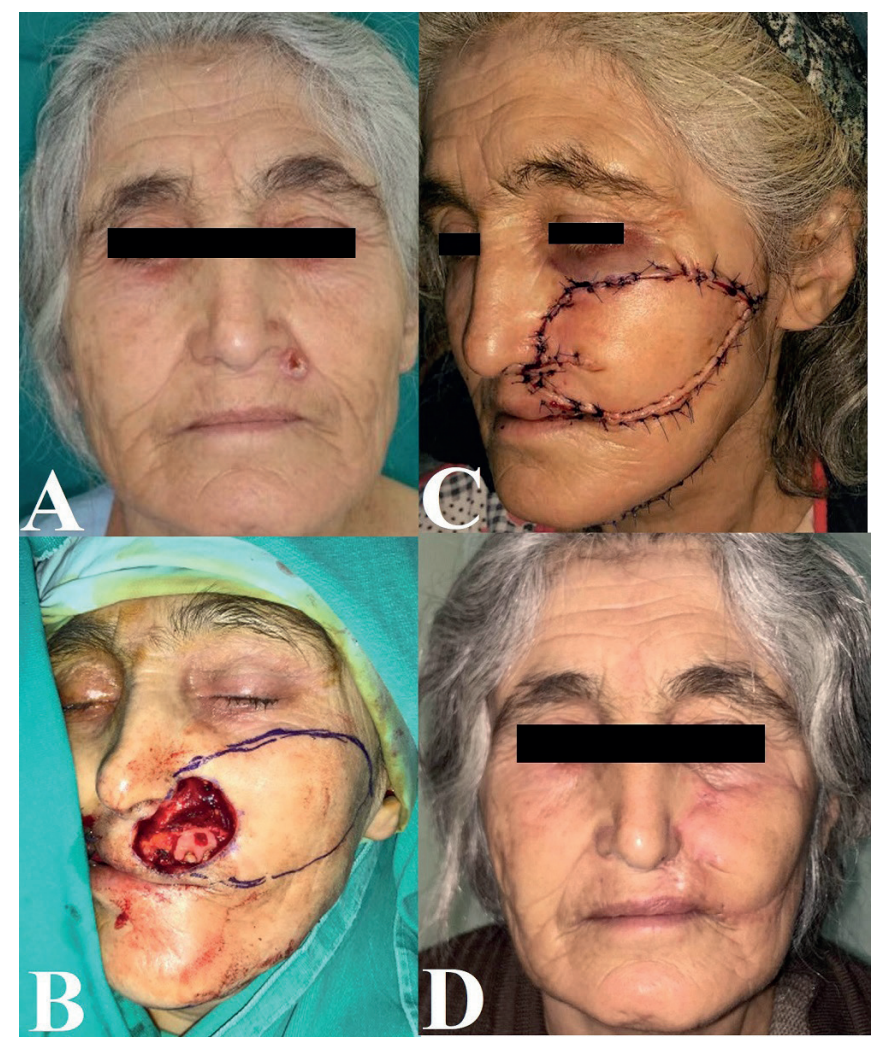

Figure 4. Preoperative (A), intraoperative (B), early postoperative $(C)$ and postoperative 6-month (D) images of case 4 (patient 29).

\section{Discussion}

Reconstruction of facial defects may be required due to various etiologies, the most common being carcinomas. These procedures are growing in number as the incidence of cancer steadily rises and because skin cancers are most often located in the facial region. ${ }^{[8]}$ The goal of facial reconstruction should be to reconstruct the facial units rather than just repair the defect. ${ }^{[9]}$
Color mismatch and contour irregularity after reconstruction are inevitable with grafts and transposition flaps and can still be apparent even years after surgery. This occurs as a result of disruption of the natural configuration of normal topographic lines, linear contraction of circular scars and permanent flap edema. With transposition flaps, arterial, venous and lymphatic circulation are provided solely by the dermal plexus, as the subcutaneous vessels must be sacrificed when the flap is lifted. V-Y advancement flaps, in which the subcutaneous circulation is preserved, generally yield a superior aesthetic outcome. ${ }^{[10]}$ In addition, the similarity of the tissue, excellent blood supply and use of the same surgical site make V-Y flaps an ideal approach. None of the patients in our series experienced permanent edema or had an aesthetically unsatisfactory outcome.

The V-Y advancement flap is traditionally considered appropriate for the repair of relatively small defects. ${ }^{[1]} \mathrm{Al}-$ though Chang et al ${ }^{[11]}$ recommended V-Y advancement flaps for defects under $3 \mathrm{~cm}$ in the algorithm they created for the selection of local flap options in the repair of midfacial defects, we were able to successfully close defects up to $6-7 \mathrm{~cm}$ in size using this flap. However, the advanced age of our patients worked to our advantage.

The biggest problem encountered in defects located near the lower eyelid-cheek junction is ectropion. ${ }^{[8]}$ The development of ectropion is associated with numerous anatomical and surgical factors such as the preexisting laxity of the tissue, the position of the maxilla relative to the orbit, the size and depth of the defect, the type of reconstructive procedure performed and the use of periosteal suspension methods. Edema in the early postoperative period worsens postoperative scarring in the long term. Therefore, late-onset ectropion is primarily due to poor surgical planning. ${ }^{[12-16]}$ In this case, the direction of the scar is important. The goal in periocular reconstruction is to achieve a stable eyelid margin, preserve symmetry, create smooth inner surfaces, ensure adequate eyelid closure to protect the globe, provide normal tension and achieve adequate horizontal and vertical eyelid dimensions for maximum function. ${ }^{[17-18]}$ For this purpose, grafts, local flaps, and in more complicated cases, free flaps are used. Although the use of grafts in the lower eyelid is common, a high ectropion rate $(14.2 \%)$ was reported in a large series. ${ }^{[19]}$ The Mustarde flap is another method used in large lower eyelid reconstructions. ${ }^{[20,21]}$ While $\mathrm{V}-\mathrm{Y}$ flaps advanced vertically are widely used in lower eyelid reconstructions, ${ }^{[8,22]}$ many authors have used these flaps with horizontal advancement. 
${ }^{[23-25]}$ In one study, it was emphasized that there was no difference in the incidence of ectropion after the use of vertically advanced V-Y flaps and Mustarde flaps. ${ }^{[8]}$ Marchac et al ${ }^{[24]}$ stated that only 1 of 21 patients who underwent lower eyelid reconstruction with horizontal advancement required ectropion correction. There are no randomized controlled studies in the English literature regarding the frequency of ectropion with these advancement flaps.

Most patients who underwent horizontal advancement in the literature had sufficient eyelid tissue for reconstruction and the flaps were prepared from these similar tissues. ${ }^{[24,25]}$ Cases with horizontal advancement of cheek tissue together with residual eyelid tissue are uncommon in the literature. When a medial defect at the cheek-lower eyelid junction is reconstructed with a horizontally advanced cheek-lateral eyelid en-bloc flap, the flap will exert only minimal tension on the lower eyelid due to its intact basal connections, thereby decreasing the risk and/or amount of ectropion. We think that this technique promises a better option rather than using conventional temporal and glabellar tissues because of the feature of this skin (case 2 and 3)..$^{[20,21]}$ In addition, we believe that the horizontal scar that forms in the long term is an advantage in terms of ectropion. Moreover, this technique makes it possible to include the entire cheek unit as a unique flap for reconstructing large flaps (case 3 and 4). It is also possible to coapt the triangular distal flap endings both to decrease suture line tension and utilize the maximum amount of similar tissue in order to obtain better cosmetic outcomes (cases 3 and 4). In such cases, the advanced age of the patients results in extra skin, and the laxity of the subcutaneous tissue increases the amount of possible advancement and enables rotation of the flap.

Regardless of the method of lower lip reconstruction, the aim is to restore muscular function, sensation, mouth opening, and adequate oral competence. Although the majority of these aims seem to be satisfied with the neurovascular musculocutaneous flap described by Karapandzic ${ }^{[26]}$ in 1974, microstomies are inevitable for large defects. $\mathrm{V}$-Y flap modifications have been previously used in lower lip reconstructions for defects of various sizes. ${ }^{[27-30]}$ When used in full-thickness lower lip reconstruction, these flaps have generally been advanced in the vertical plane. Satisfactory functional and aesthetic results have been reported with this $\mathrm{V}-\mathrm{Y}$ modification in lower lip reconstructions. ${ }^{[27-29,31]}$ In these modifications, the flaps were advanced from downward to upward position and muscle repair was achieved. In our technique, bilateral flaps were advanced in the horizontal plane and the orbicularis oris muscles were repaired in a circular manner similar to the Karapazanzic flap. Microstomy was also avoided due to simultaneous commissurotomy while the flaps were prepared (case 1). We believe that our modification is more advantageous than vertical V-Y advancements, as it allows horizontal advancement and repair of the orbicularis muscle.

Although the aim of upper lip reconstructions is the same as in lower lip reconstructions, the options are more limited due to the anatomic adjacencies. In addition, they include more complex aesthetic structures such as the philtral columns and cubid's bow. In these reconstructions, the superior adjacent nostril opening and its symmetry should be preserved. In upper lip reconstructions, the most appropriate tissue is undoubtedly the remaining part of the upper lip or the lower lip. For defects with sufficient vermilion tissue or those in which vermilion continuity is spared, the reconstruction should be done providing symmetrical vertical length with adjacent tissue options without damaging the vermilion structure to achieve optimal aesthetic outcomes. In upper lip reconstructions, V-Y flaps have been used in reconstructions of both full- and partial-thickness defects. ${ }^{[32-34]}$ In our patient who necessitated upper lip reconstruction due to her left nasolabial sulcus tumor, continuity of the vermilion was spared and tissue from the ipsilateral cheek was used. The cheek defect was closed with cheek tissue, while the proximal lower leg of the V-Y flap was used to ensure symmetry of the vertical height of the upper lip.

In conclusion, $\mathrm{V}-\mathrm{Y}$ flaps can be reliably used on the face. They are not only applicable with medium and small defects, but can be used for all defects with sufficient surrounding tissue. They enable various modifications and the elevation of multiple flaps. Joining the proximal ends along the longitudinal axis of the flap extends the length of the flap, especially in areas that do not allow for a second flap. In cases where the use of this maneuver is foreseen, less advancement will be necessary if the flap is planned to include a broader area of tissue around the defect. Such planning is particularly beneficial in aesthetic transition areas because the amount of required tissue will change. Thus, the proximal ends of the flap are rotated in different directions to enable appropriate reconstructions. This allows the defect to be closed with a single flap. Again, if the flap is mobilized sufficiently, different degrees of rotation are possible depending on the thickness of the subcutaneous 
fatty tissue. This increases our adaptation options. While the flap is being created, large flaps can be prepared to include an entire aesthetic unit. Advancement of the flap is easier in older patients but may be slightly more limited in younger individuals. It should be remembered that the amount of advancement will be different in different parts of the face. These flaps are a type of island flap and provide good color and tissue match. Because the base connections are not disrupted, they maintain tissue statics and dynamics better than other flap options that are separated from their base.

\section{Acknowledgements: None.}

Ethics Committee Approval: Approval was obtained from Cumhuriyet University Ethics Committee (decision no: 2018-04\37, date: April 30, 2018).

\section{References}

1. Rao JK, Shende KS. Overview of Local Flaps of the Face for Reconstruction of Cutaneous Malignancies: Single Institutional Experience of Seventy Cases. J Cutan Aesthet Surg 2016;9:220-5.

2. Venkataramakrishnan V, Mohan D, Villafane O. Perforator based V-Y advancement flaps in the leg. Br J Plast Surg 1998;51:431-5.

3. Akan IM, Ulusoy MG, Bilen BT, Kapucu MR. Modified bilateral advancement flap: the slide-in flap. Ann Plast Surg 1999;42:545-8.

4. Emmett AJ. The closure of defects by using adjacent triangular flaps with subcutaneous pedicles. Plast Reconstr Surg 1977;59:45-52.

5. Ulusoy MG, Akan IM, Sensöz O, Ozdemir R. Bilateral, extended V-Y advancement flap. Ann Plast Surg 2001;46:5-8.

6. Ichioka S, Okabe K, Tsuji S, Ohura N, Nakatsuka T. Distal perforator-based fasciocutaneous V-Y flap for treatment of sacral pressure ulcers. Plast Reconstr Surg 2004;114:906-9.

7. Kimyai-Asadi A, Goldberg LH. Island pedicle flap. Dermatol Clin 2005;23:113-27

8. Sugg KB, Cederna PS, Brown DL. The V-Y advancement flap is equivalent to the Mustardé flap for ectropion prevention in the reconstruction of moderate-size lid-cheek junction defects. Plast Reconstr Surg 2013;131:28-36.

9. Menick FJ. Defects of the nose, lip, and cheek: rebuilding the composite defect. Plast Reconstr Surg 2007;120:887-98.

10. Kalus R, Zamora S. Aesthetic considerations in facial reconstructive surgery: the V-Y flap revisited. Aesthetic Plast Surg 1996;20:83-6.

11. Chang JW, Lim JH, Lee JH. Reconstruction of midface defects using local flaps: an algorithm for appropriate flap choice. Medicine (Baltimore) 2019;98:18021.

12. Hintschich C. Correction of entropion and ectropion. Dev Ophthalmol 2008;41:85-102.
Informed Consent: Informed consent was obtained from all individual participants included in the study.

Author Contributions: Designing the study - H.D., K.I.U.; Collecting the data - H.D., K.I.U.; Analysing the data - H.D., SY.; Writing the manuscript - H.D., SY.; Confirming the accuracy of the data and the analyses H.D., SY., K.I.U.

Conflict of Interest: The authors have no conflicts of interest to declare.

Financial Disclosure: The authors declared that this study has received no financial support.

13. Robinson JK. Suspension sutures in facial reconstruction. Dermatol Surg 2003;29:386-93.

14. Harris GJ, Perez N. Anchored flaps in post-Mohs reconstruction of the lower eyelid, cheek, and lateral canthus: avoiding eyelid distortion. Ophthalmic Plast Reconstr Surg 2003;19:5-13.

15. Hudson DA, Quarmby C, Ndobe E. A suture suspension technique to prevent ectropion after flap transposition from the neck to the face. Plast Reconstr Surg 2001;108:1692-5.

16. Salasche SJ, Jarchow R, Feldman BD, Devine-Rust MJ, Adnot J. The suspension suture. J Dermatol Surg Oncol 1987;13:973-8.

17. Hayano SM, Whipple KM, Korn BS, Kikkawa DO. Principles of Periocular Reconstruction following Excision of Cutaneous Malignancy. J Skin Cancer 2012;2012:438502.

18. Czyz CN, Cahill KV, Foster JA, Michels KS, Clark CM, Rich NE. Reconstructive options for the medial canthus and eyelids following tumor excision. Saudi J Ophthalmol 2011;25:67-74.

19. Rubin P, Mykula R, Griffiths RW. Ectropion following excision of lower eyelid tumours and full thickness skin graft repair. Br J Plast Surg 2005;58:353-60.

20. Mustardé JC. The use of flaps in the orbital region. Plast Reconstr Surg 1970;45:146-50.

21. Callahan MA, Callahan A. Mustardé flap lower lid reconstruction after malignancy. Ophthalmology 1980;87:279-86.

22. Peled I, Kaplan H, Wexler MR. Lower eyelid reconstruction by V-Y advancement cheek flap. Ann Plast Surg 1980;5:321-3.

23. Acikel C, Celikoz B, Yildiz TF. Y-shape hard palate mucoperiosteal graft and $\mathrm{V}-\mathrm{Y}$ advancement flap in the reconstruction of a combined defect involving lateral canthus and upper and lower eyelids. Ann Plast Surg 2004;52:97-101. 
24. Marchac D, de Lange A, Bine-bine H. A horizontal V-Y advancement lower eyelid flap. Plast Reconstr Surg 2009;124:1133-41.

25. Monarca C, Rizzo MI, Marcasciano M, Parisi P, Ruggiero M, Scuderi $\mathrm{N}$. A horizontal V-Y advancement lower eyelid flap: our experience performing a bilateral suspension to the periosteum. Plast Reconstr Surg 2012;130:178-80.

26. Karapandzic M. Reconstruction of lip defects by local arterial flaps. Br J Plast Surg 1974;27:93-7.

27. Bayramiçli M, Numanoğlu A, Tezel E. The mental V-Y island advancement flap in functional lower lip reconstruction. Plast Reconstr Surg 1997;100:1682-90.

28. Bocchi A, Baccarani A, Bianco G, Castagnetti F, Papadia F. Double V-Y advancement flap in the management of lower lip reconstruction. Ann Plast Surg 2003;51:205-9.

29. Fang QG, Shi S, Zhang X, Li ZN, Liu FY, Sun CF. Total lower lip reconstruction with a double mental neurovascular V-Y island advancement flap. J Oral Maxillofac Surg 2014;72:834.
30. Kakudo N, Kuro A, Morimoto N, Hihara M, Kusumoto K. Combined Tongue Flap and Deepithelialized Advancement Flap for Thick Lower Lip Reconstruction. Plast Reconstr Surg Glob Open 2017;5:1513.

31. Chen WL, Wang YY, Zhou M, Yang ZH, Zhang DM. Double mental neurovascular V-Y island advancement flaps combined with tongue flaps for functionally reconstructing total lower-lip defects. J Craniofac Surg 2012;23:181-3.

32. Thorpe RB, Smith JM, Srivastava D. Repair of a Full-Thickness Defect of the Right Upper Lip Extending Into Multiple Cosmetic Subunits. Dermatol Surg 2019;45:731-3.

33. Carvalho LM, Ramos RR, Santos ID, Brunstein F, Lima AH, Ferreira LM. V-Y advancement flap for the reconstruction of partial and full thickness defects of the upper lip. Scand J Plast Reconstr Surg Hand Surg 2002;36:28-33.

34. Zeitouni NC, Ang JM, Weyer CW, Krunic AL. Horizontally Opposed V-Y Advancement Flaps for Surgical Reconstruction of Central Upper Lip Defects. J Craniofac Surg 2017;28:578-9. 